\title{
Some aspects regarding the relationship between consumer and Industrial Design
}

\author{
Andrei Dumitrescu* \\ Politehnica University of Bucharest, Department of Manufacturing Engineering, \\ 313 Splaiul Independentei, Bucharest 060042, Romania
}

\begin{abstract}
The product manager, as the leader of product-related activities, has the task of identification the product's main features that will distinguish it on the market. Some of these will be related to the industrial design. This paper presents the results of an experiment designed to explore the relationship between consumer and industrial design. The experiment addressed issues like the consumer's awareness of industrial design, its influence on product assessment, etc.
\end{abstract}

\section{Introduction}

The globalization has made a world in which the competition is tougher than ever. When approaching this subject, academic authors and speakers use to quote brand guru David A. Aaker [1]. He discussed with thousands of CEOs and almost all of them complained about the high competition in their field. Only one was the exception: the director of Panama Canal. But it seems that even that one will have competition: Nicaragua's National Assembly has approved plans to make a connecting channel through their country [2].

Because of large funds invested in technological research, the technology is progressing at a high rate and new improved products appear on the market at shorter intervals of time. In order to cope with quality issues, the vast majority of companies implemented quality management systems (ISO 9000, etc.). So, the cases of poor quality products manufactured by regular companies are very rare.

The result is that the market is flooded with very similar products, possessing almost identical functions with parameter values in a very close interval and at the same (more or less) price. More, the quality is guaranteed for years. The consequence is the impasse of the consumer. How a consumer visiting a virtual shop on internet can easily and reliably choose among hundreds of very similar products?

There are two main strategies that today consumers are using: they rely on well-known and trusted brands or they let themselves "seduced" by the product's industrial design, assuming that a company that invested in product aesthetics also invested in practical functions, usability and quality.

The experts studied the consumer responses to products and discovered that cognition and affect influences the buying behaviour [3, 4]. Behavioural responses are: approach and avoid. The approach response triggers further investigation of the product, leading to a

*Corresponding author: andrei.dumitrescu@upb.ro 
possible purchase, while the avoid response directs to the ignoring of the product. More indepth, it was shown that consumers observing a product attain pleasure from reflecting about its quintessence and not just from pure sensorial inputs [5].

However, the consumer literature generally presents the consumer as a simple observer of the products, who ignores the fact that these products were conceived accordingly to a design specification; and especially that the products were designed to be regarded by the consumer in a particular way. Just few works highlight this particular aspect $[6,7,8,9]$.

Nathan Crilly [9] considers that in some situations consumers can be unaware of the fact that products have been designed, but in other situations they are aware of the design aspect and this influences their reaction. Consumers can inference from the product features and the designer's intentions. These intensions might be: eliciting attention; emphasising the manufacturer's brand; creating attraction towards the product; attribution of meanings; etc.

Crilly [9] chose the mobile phones as the subject of his investigations and the interview as method. By asking questions like: "What do you like or dislike about your mobile phone?", "Why do you think your phone is the way it is?" and "When you are looking at, or using, products such as mobile phones, how aware are you that those products have been designed?", he found evidence for the inference process related to the designer's intentions.

The topic of knowledgeably and not-knowledgeably persons was approached by Odette da Silva, Nathan Crilly and Paul Hekkert [10]. They used students from an industrial design programme and product images \& designer intention statements from student projects. Among other conclusions, they discovered that knowing designer intentions enhanced the positive assessment of products. Going further with the reasoning, the researchers assumed that consumers can learn about the designers' intentions from statements made by designers, press releases, marketing campaigns, critical reviews, etc. So, the designers, manufacturers and publicity agencies should directly advertise their intentions in order to get a favourable consumer assessment.

\section{Design of experiment}

Analysing carefully the results obtained by other researchers, some significant aspects has emerged. In one investigation, mobile phones were used, but it should be mentioned that mobile phones are very personal and involving products, so consumers are more sensitive to all information related to them, including the fact that they have a "designed" status. So, an experiment based on more mundane products should lead to more relevant results.

Another important aspect is related to the use of products (and design statements) from student projects in an experiment with design students as participants. Inevitably, a student project is a by-the-book endeavour, meaning that all design phases are fully completed (including a design statement). In the practical world, some design phases are skipped or partially completed. So, a design statement could be missing for an average product. Also, the design students are definitely more sensitive to design statements than the average consumer. Finally, as indicated above, the consumer is usually overwhelmed by the number of the products available on the market and an associated design statement for each of them (more likely very similar) would make no difference. The design statement would be really relevant for sought-after products (very personal or very expensive etc.).

Without disregarding the results obtained from the researches mentioned above, the author of the present paper considers that the results of a new experiment aimed at average consumers and using a very mundane type of product will complete the knowledge in the field of the complex relationship between consumer and industrial design.

The selected type of product was the set of salt and pepper shakers. In experiment, there were used images of four sets of salt and pepper shakers, considering the third set (the most simple and mundane) as reference. These sets are displayed in Figures $1-4$. 


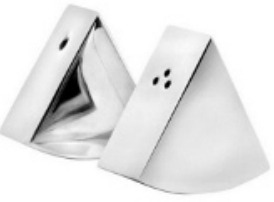

Fig. 1. Set 1.

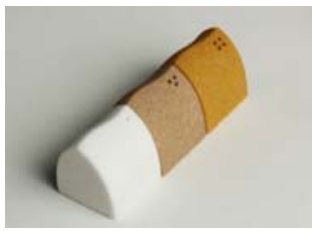

Fig. 2. Set 2.

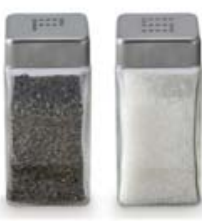

Fig. 3. Set 3 .

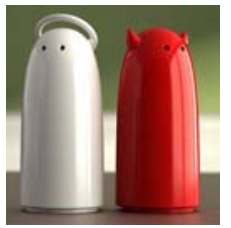

Fig. 4. Set 4.

It was decided that the participants will be students from a technical university. This narrowed the addressed population, but increased the relevance of experiment for the younger population. Also, this eased conducting of experiment.

After reviewing the similar experiments, it was decided to use the following questions:

1. Indicate the aesthetic value of the product. [ $\left[\begin{array}{ll}1 & \ldots\end{array}\right]$

2. What do you like at the product? [open question]

3. What do you dislike at the product? [open question]

4.Indicate your impression regarding the product using only one adjective. [open question]

5. Why do you think that the product had been designed with the features indicated by you? [open question]

6. Indicate again the aesthetic value of the product. (You can indicate the same value as before or a different one.) [1 ... 7]

The reason for repeating the first question similar at the end was to determine if the participant is changing her/his assessment after thinking about the product features and the "designed" character of the product.

\section{Experimental results}

The experiment was performed with 161 participants ( 81 female and 80 male participants). All participants were students enrolled at a large technical university in Romania. The participants filled the same questionnaire with 6 questions per product.

The open responses were analysed individually and the essence of the response was recorded. The essence was a feature or a quality. Some features and qualities were general (shape, colour, etc.), others were product specific (antithesis, etc.).

Table 1. Products' features and qualities liked by participants.

\begin{tabular}{|l|c|c|c|c|}
\hline Like [\%] & Product 1 & Product 2 & Product 3 & Product 4 \\
\hline Shape & 51.06 & 27.84 & 16.99 & 32.45 \\
\hline Colour(s) & 15.43 & 42.61 & NR & 22.34 \\
\hline Texture & 5.85 & 5.68 & NR & NR \\
\hline Material & 7.98 & 2.84 & NR & NR \\
\hline Design & 13.30 & 7.95 & 7.84 & 13.83 \\
\hline Utility & NR & NR & 38.57 & NR \\
\hline Significance & NR & NR & NR & 19.15 \\
\hline Simplicity & NR & NR & 22.22 & NR \\
\hline Antithesis & NR & NR & NR & 5.32 \\
\hline Other & 6.38 & 13.07 & 14.37 & 6.91 \\
\hline \multicolumn{1}{|c|}{ Total } & 100 & 100 & 100 & 100 \\
\hline
\end{tabular}

Note: $N R$ - not relevant values 
The products' features and qualities liked by the participants are displayed in Table 1. (Note that a set of shakers was considered as a single product.)

Analysing the results from Table 1, it can be observed that shape and colour were the most used features in the assessment of liked features. Texture and material were used only when they possess on outstanding character (as for products 1 and 2). Design (as an integrative feature for product aesthetics) was entailed seldom. Only when the industrial design was poor, participants were considering qualities like utility and simplicity (product 3 ). When the product's message was eloquent, people were more inclined to reflect upon the significance circulated by the design object and considered even possible "figures of speech", like antithesis. Concluding, participants were assessing the industrial design in the first instance, taking utility as granted and, only when design was poor, they took into account the utility.

When analysing the disliked features and qualities, it was observed that people were very precise and analytic about what they do not like, more than in the case of liked characteristics. It was like they were afraid to choose the wrong product. The products' features and qualities disliked by the participants to experiment are displayed in Table 2.

Table 2. Products' features and qualities disliked by participants.

\begin{tabular}{|l|c|c|c|c|}
\hline Dislike [\%] & Product 1 & Product 2 & Product 3 & Product 4 \\
\hline Shape & 18.87 & 27.85 & 22.54 & 23.59 \\
\hline Colour(s) & 23.90 & 27.85 & 7.04 & 15.73 \\
\hline Texture & NR & 5.06 & NR & NR \\
\hline Material & 11.32 & 6.33 & 7.75 & 6.74 \\
\hline Design & NR & 4.43 & 4.93 & 2.24 \\
\hline Size & 3.77 & 6.33 & NR & 7.86 \\
\hline Holes & 8.81 & 8.86 & 4.93 & 13.48 \\
\hline Utility & 10.07 & NR & NR & NR \\
\hline Triviality & NR & NR & 29.58 & NR \\
\hline Other & 23.27 & 13.29 & 23.23 & 30.36 \\
\hline \multicolumn{1}{|c|}{ Total } & 100 & 100 & 100 & 100 \\
\hline
\end{tabular}

Note: NR - not relevant values

Again, the shape and colour were used as assessment criteria, but in a lesser degree comparing to the liked features. Texture was an insignificant feature, but material had a greater importance than previously. Design was less considered than before, but now even less. Size was an assessment criterion, but considered only by few participants. Utility was ignored with the notable exception of product 1 , which raised the fear of instability. The triviality of "poor" design (product 3) was the most annoying characteristic. If in the previous assessment the holes were seldom mentioned, the holes (especially position and size) were indicated by several participants. A special mentioned should be made about product 4 which was totally liked by $54 \%$ participants (no disliked features).

Even if the question regarding the adjectives was aimed primarily to make participants to think more about products' design, also this question lead to significant results. The adjective used by participants are displayed in Table 3.

Because it was an open question, the participants used a large range of adjectives and the individual weight of almost all adjectives was relatively low (lower than $6.8 \%$ ). The notable exceptions were "simple" $(15.53 \%)$ for product 3 and "funny" for product 4 . Actually, these two adjectives were obvious when looking at the two products. Reasonable 
choices for adjectives were "beautiful", "nice", "simple", "funny" and "playful". When some participants were in doubt what adjective to use, they chose "interesting".

Table 3. Adjectives used by participants.

\begin{tabular}{|c|c|c|c|c|c|c|c|}
\hline \multicolumn{2}{|c|}{ Product 1 [\%] } & \multicolumn{2}{c|}{ Product 2 [\%] } & \multicolumn{2}{c|}{ Product 3 [\%] } & \multicolumn{2}{c|}{ Product 4 [\%] } \\
\hline Modern & 9.32 & Interesting & 5.59 & Simple & 15.53 & Funny & 14.29 \\
\hline Interesting & 5.59 & Beautiful & 4.97 & Trivial & 9.94 & Beautiful & 6.21 \\
\hline Simple & 5.59 & Nice & 4.97 & Classic & 9.32 & Interesting & 6.21 \\
\hline Beautiful & 4.97 & Weird & 3.73 & Mundane & 6.83 & Playful & 5.59 \\
\hline Elegant & 3.73 & Modern & 3.73 & Useful & 5.59 & Modern & 5.59 \\
\hline Nice & 3.73 & Cute & 3.11 & Nice & 4.35 & & \\
\hline Cold & 3.73 & & & Beautiful & 3.73 & & \\
\hline Other & 63.36 & Other & 73.91 & Other & 44.72 & Other & 62.11 \\
\hline Total & 100 & Total & 100 & Total & 100 & Total & 100 \\
\hline
\end{tabular}

The responses to the open question "Why do you think that the product had been designed with the features indicated by you?" are synthesised in Table 4.

Table 4. Intentions attributed to designers.

\begin{tabular}{|c|c|c|c|c|c|c|c|}
\hline \multicolumn{2}{|c|}{ Product 1 [\%] } & \multicolumn{2}{|c|}{ Product $2[\%]$} & \multicolumn{2}{|c|}{ Product 3 [\%] } & \multicolumn{2}{|c|}{ Product 4 [\%] } \\
\hline $\begin{array}{l}\text { To be sold } \\
\text { well }\end{array}$ & 16.15 & $\begin{array}{l}\text { To grab } \\
\text { attention }\end{array}$ & 18.13 & For utility & 42.24 & $\begin{array}{l}\text { To grab } \\
\text { attention }\end{array}$ & 22.36 \\
\hline $\begin{array}{l}\text { To grab } \\
\text { attention }\end{array}$ & 14.29 & $\begin{array}{l}\text { To be } \\
\text { distinguished }\end{array}$ & 11.25 & $\begin{array}{l}\text { For } \\
\text { simplicity }\end{array}$ & 7.45 & $\begin{array}{l}\text { To be sold } \\
\text { well }\end{array}$ & 16.77 \\
\hline For utility & 13.66 & $\begin{array}{l}\text { To be sold } \\
\text { well }\end{array}$ & 10.63 & $\begin{array}{l}\text { To be sold } \\
\text { well }\end{array}$ & 7.45 & $\begin{array}{l}\text { For } \\
\text { amusement }\end{array}$ & 12.42 \\
\hline $\begin{array}{l}\text { To look } \\
\text { modern }\end{array}$ & 6.83 & For utility & 10.00 & $\begin{array}{l}\text { For lowering } \\
\text { costs }\end{array}$ & 6.21 & $\begin{array}{l}\text { To be } \\
\text { distinguished }\end{array}$ & 6.21 \\
\hline $\begin{array}{l}\text { To be } \\
\text { distinguished }\end{array}$ & 5.59 & To look nice & 7.50 & $\begin{array}{l}\text { To grab } \\
\text { attention }\end{array}$ & 3.11 & For utility & 6.21 \\
\hline $\begin{array}{l}\text { To match the } \\
\text { market needs }\end{array}$ & 3.73 & $\begin{array}{l}\text { To match the } \\
\text { market needs }\end{array}$ & 5.00 & & & To look nice & 4.97 \\
\hline Other & 39.76 & Other & 37.50 & Other & 33.54 & Other & 31.06 \\
\hline Total & 100 & Total & 100 & Total & 100 & Total & 100 \\
\hline
\end{tabular}

Among the relevant intentions attributed to designers, there should be made a distinction between objective intentions and subjective intentions. The former category includes "for utility", "to match the market needs", "for simplicity", "to look nice", "for amusement" and "to look modern" and the latter - "to grab attention", "to be sold well" and "for lowering costs". Unfortunately, the participants felt that the subjective intentions are prevalent when the design is more elaborate.

Odette da Silva, Nathan Crilly and Paul Hekkert [10] discovered, in an experiment briefly described in introduction, that people who are aware of designer's intentions are more inclined to enhance their positive assessment of products. Because of the reasons indicated in "Design of experiment" section, the designer's intentions were not used, but participants were persuaded to think about the "designed" character of products in the Crilly's manner [9]. They were asked to assess the aesthetic value of the products at the beginning and at the end of the questionnaire. The mark averages are displayed in Table 5. 
Table 5. Average aesthetic values - before and after [max. 7].

\begin{tabular}{|c|c|c|c|c|c|c|c|}
\hline \multicolumn{2}{|c|}{ Product 1 [\%] } & \multicolumn{2}{c|}{ Product 2 [\%] } & \multicolumn{2}{c|}{ Product 3 [\%] } & \multicolumn{2}{c|}{ Product 4 [\%] } \\
\hline Before & After & Before & After & Before & After & Before & After \\
\hline 5.09 & 5.11 & 4.46 & 4.44 & 4.01 & 4.02 & 5.78 & 5.88 \\
\hline
\end{tabular}

It can be easily observed that only in the case of elaborate design with a clear message (product 4), the awareness of the "designed" character determined participants to increase their assessment marks. In the case of mundane design or even neat design, thoughts about the designed character did not improve the assessment of industrial design.

So, reasoning about the product's aesthetics, its "designed" character, and probable designer's intentions does not improve the results of aesthetic assessment of usual products, with the exception of products with an elaborate design. This exception partially confirms the results obtained by researchers that used products designed by-the-book and students enrolled at a design programme as participants to research.

\section{Conclusions}

An experiment was conducted using usual products (four sets of salt and pepper shakers). The participants to the experiment were university students. Because university students can easily be consumers of salt and pepper shakers, the experiment conclusions can be drawn for consumers. The conclusions are:

Shape and colour are the main features assessed by consumers when asked about what they like or dislike about a certain product. Texture and material are considered only when these features possess an outstanding character. The overall design is considered as an assessment criterion by few consumers. Utility is assessed only when the industrial design is disappointing or when there are doubts about the product's proper functioning. Significance is considered only if the message was really eloquent. Triviality of poorconceived design can be the most annoying characteristic.

The choices for adjectives to describe product's design can be from a large palette, if the design is not striking in a certain way. "Interesting" is used by consumers as an escape option when judging design.

Consumers consider that an elaborate design indicates rather subjective design intentions like grabbing attention and increasing the sales. Consumers associate a professional designer contribution only with products with an elaborate and neat design.

Consumers enhance their aesthetic assessment of products as a result of the awareness of the "designed" character only in the case of elaborate design.

\section{References}

1. D.A. Aaker, Building Strong Brands (Simon \& Schuster, 2010)

2. https://en.wikipedia.org/wiki/Nicaragua_Canal

3. P.H. Bloch, J. Marketing, 59(3), 16 (1995)

4. J. O'Shaughnessy, Explaining buyer behavior (Oxford University Press, 1992)

5. P. Bloom, How pleasure works: Why we like what we like (Vintage, 2011)

6. N. Crilly, J. Moultrie, P. J. Clarkson, Design Studies, 25(6), 547 (2004)

7. M.E.H. Creusen, J. P. L. Schoormans, J. Prod. Innov. Manag. 22(1), 63 (2005)

8. P.M.A. Desmet, P. Hekkert, I. J. Design 1(1), 57 (2007)

9. N. Crilly, I. J. Design, 5(3), 1 (2011)

10. O. Da Silva, N. Crilly, P. Hekkert, I. J. Design, 9(2), 21 (2015) 